\title{
The Values of Physical Landscape in Accommodating Social Sustainability of Traditional Malay Settlement
}

\author{
Najiha Jaffar, Nor Zalina Harun \\ Institute of The Malay World and Civilization, \\ The National University of Malaysia, 43600 Bangi, Selangor, Malaysia \\ najihajaffar13@gmail.com,nzalina@ukm.edu.my \\ Tel : +60192490357
}

\begin{abstract}
Traditional settlements are one of the many valuable possessions in terms of history, culture and architecture. However, modernization have altered the physical landscape and destroyed these important social spaces by replacing them with more modern public infrastructure. This study aims to investigate how the multiple physical aspects of public infrastructure in traditional settlement environment play a role in supporting the welfare of the community. This research using mixed-methodology includes observation, questionnaires and interviews. The main findings shows the main factors of good public spaces; (i) sufficient facilities; (ii) accommodate a variety of activities; (iii) provide convenience to the public.
\end{abstract}

Keywords: physical landscape; public spaces; public infrastructure; social sustainability; traditional settlement

eISSN: 2398-4287C 2020. The Authors. Published for AMER ABRA cE-Bs by e-International Publishing House, Ltd., UK. This is an open access article under the CC BYNC-ND license (http://creativecommons.org/licenses/by-nc-nd/4.0/). Peer-review under responsibility of AMER (Association of Malaysian Environment-Behaviour Researchers), ABRA (Association of Behavioural Researchers on Asians) and cE-Bs (Centre for Environment-Behaviour Studies), Faculty of Architecture, Planning \& Surveying, Universiti Teknologi MARA, Malaysia.

DOI: https://doi.org/10.21834/ebpj.v5i15.1858

\subsection{Introduction}

A traditional settlement is among the fundamental assets of an important value in terms of history, customs, culture, and architecture that can develop a society's identity of a country. In this study, the traditional Malay settlement is define as an area that is inherited and inhabited by the Malay community for their generation with an integrated village environment and a physical landscape environment based on a Malay settlement concept (Authority, 2011; Wei, 2015). It is also a place, which supports cultural diversity, tradition and identity of each community in this country. The traditional settlements are the imprints of our past that act as a living museum to inform us of our root, identity, values and response to the development of our current built environment (Sulaiman, Samsuddin \& Amat (2012). Nevertheless, the existence of traditional settlements nearby contemporary cities is considered vulnerable and underdeveloped which can lead them to destruction for the sake of development. The traditional Malay settlement is currently facing the loss of identity. Over the years, modernization and progress have directly and indirectly altered the local lifestyle and identity. The expansion of new cities in a country has diminished the physical and cultural landscape especially for traditional settlements (Ariffin, 2007). This loss of identity is due to the ambiguity of functions and the importance of physical landscapes and the alterations of space patterns caused by development.

\subsection{Aims and objectives}

This study aims to analyze how the multiple physical aspects of public infrastructure and traditional settlement environment around Kuala Terengganu play the role in supporting the welfare of the community. The first objective is to identify the typologies of public

eISSN: 2398-4287C 2020. The Authors. Published for AMER ABRA cE-Bs by e-International Publishing House, Ltd., UK. This is an open access article under the CC BYNC-ND license (http://creativecommons.org/licenses/by-nc-nd/4.0/). Peer-review under responsibility of AMER (Association of Malaysian Environment-Behaviour Researchers), ABRA (Association of Behavioural Researchers on Asians) and cE-Bs (Centre for Environment-Behaviour Studies), Faculty of Architecture, Planning \& Surveying, Universiti Teknologi MARA, Malaysia.

DOI: https://doi.org/10.21834/ebpj.v5i15.1858. 
infrastructure in the traditional Malay settlement and the second objective is to investigate the functions of public infrastructure supporting the social sustainability of the traditional Malay settlement community.

\subsection{Literature Review}

A new development in a settlement constructed without considering the population's interests therefore eliminating the social interaction place of the community. This refers to the increasing housing projects in rural areas that are built with disregard towards Malay societal values and culture that have been practised for generations in the area. As stated by Rasdi (2011), the lack of space for community ceremonies such as weddings and funeral arrangements, the need for such space is increasingly neglected by most modern housing design today. The study by Ghoomi et al. (2015) stated that the development of a modern city reduces the quality of social relations in a society and changes the physical pattern of the residential area.

\subsection{Elements of Physical Landscape and Public Infrastructure}

The concept of landscape in geography is a dynamic system with a spatial structure formed by natural and cultural elements (Bobek \& Schmithüsen, 1998). Landscapes include geophysically formed physical elements of terrain comprising mountains, hills, and water streams such as rivers, lakes, ponds, and seas, as well as the elements of life covering the earth including indigenous plants, and manmade elements of various forms of land use, buildings, and structures, and temporary elements such as lighting and weather conditions. Landscaping according to Leibenath and Gailing (2012) is (1) a physical space or ecosystem complex; (2) in the context of the relationship between humans and the environment; (3) a figurative expression; and (4) a social construct, or a term in everyday discourse. As for the term physical landscape, according to Berglee (2012), physical landscape is a term used to describe the natural area in any place on this earth.

According to Pickering (1994), a physical landscape acts as a component of the cultural landscape whereby the physical landscape merges with the social landscape immortalized as a model, to ensure location and life occur simultaneously in harmony from both the symbolic and material dimensions of life. Pickering (1994) also states that a physical landscape is an element that forms the measure of the social landscape, namely through the characteristics of settlement patterns, the spatial and temporary spread of historical occupations, topographic and environmental features, and characteristics of the main drainage areas. Meanwhile, the term 'cultural landscape' is the interaction between humans and nature that should be evaluated in a very broad perspective that encompasses crosscultural and historical studies (Rapoport, 1976). In other words, culture is the agent whereas the natural area (physical landscape) is the medium and the cultural landscape is the result (Sauer, 1925). Based on the aforementioned definition, a physical landscape is one of the important elements in the components of a cultural landscape. In the context of this study, a physical landscape is a physical element that shapes human life with optimal well-being and can establish sustainable social qualities whether man-made or natural elements.

Public infrastructure in this study refers to the public space namely a gathering space or social space generally open and accessible by the public (Sakip, Akhir and Omar, 2015; Parker \& Simpson, 2018). Public space should be easily accessible from various directions and provides a variety of activities (Pasaogullari and Doratli, 2004; Sugiyama and Thompson, 2007 and de Sousa Silva, Viegas \& Bell, 2018) and functions that are inclined to be attractive public spaces and can be used for social activities to promote social interaction (Barrera et al., 2016). A good public space is important to connect people with the environment to promote and provide space for physical activities and improve health while benefiting community relations (Gehl's, 2002). Public space can be measured based on the factors of availability of facilities and sufficient space to accommodate sports and recreational activities, accommodate different activities at different times, and provide facilities to enjoy comfort and tranquillity. According to Abdul Rahman, Shamsuddin, and Ghani (2015), this factor can be measured and evaluated based on the number of attendees, social networks, and the lives of different social groups.

\subsection{Social sustainability}

Social sustainability is generally defined as the maintenance and improvement of the well-being of current and future generations (Michael \& Peacock, 2011). According to McKenzie, (2004), this includes equity of access to key services (including health, education, transportation, housing, and recreation), as well as equity across generations, which means that the activities of the current generation also benefit future generations. However, Davidson and Wilson (2009) suggested that social sustainability is a system of cultural relations wherein the positive aspects of different cultures are valued and promoted.

According to the Youth Foundation in their framework of creating a new community (Woodcraft, Hackett \& Caistor-Arendar, 2011), social sustainability is defined as "the process of creating a sustainable place and succeeds to promote well-being, by understanding what the community needs". Continuous social interaction is a two-way communication process that involves two or more individuals or groups at a particular place and time (Bardis, 1979; Lotfata \& Ataöv, 2020; Kader \& Mahmoud, 2019). In this study, the social interaction relationship takes place in public spaces and fosters understanding, tolerance, cooperation, making acquaintances, and helping each other for everyone's benefit. These qualities are essential for the formation of a progressive, integrated, and harmonious society.

\subsection{Relation between Physical Landscape and Social Sustainability}

We will not be able to achieve a prosperous quality of life if we only assess social sustainability based on non-physical elements such as employment, education, health, governance, and so on. This participation can be enhanced when residents have the opportunity to interact with each other such as being easily contacted, living close to others, and having a suitable space to carry out activities (Festinger et al., 1950). 
In achieving quality social sustainability, physical aspects such as public spaces need to be given due attention. Public space, also known as the physical landscape, plays a key role in determining the prosperity of life and encouraging social participation in society (Moulay, Ujang \& Said, 2017). This means that sustainable social prosperity should integrate physical design with social design as well. For example, providing infrastructure to support social and cultural life, providing systems involving communities, providing space for people and space to evolve (González, Henríquez \& Sierra, 2020; Karimnia \& Haas, 2020). In addition to completing this definition, the character of the residential environment and social spaces is also one of the key elements in the foundation of social sustainability to ensure a quality social and community development.

\subsection{Methodology}

\subsection{Study area}

Kampung Pulau Duyong is famously known as a seafarer's village developed in the late 16th century. The village is separated from the mainland by the Terengganu River. The settlement is made up of more than 10 villages, namely Pulau Ketam, Kampung Kelab Ayer, Kampung Duyong Sekolah, Kampung Wan Su, and Kampung Pulau Duyong Kecil. Before 1985, Pulau Duyong originally consisted of only Pulau Duyong Besar and Pulau Duyong Kecil separated from each other by shallow rivers. However, due to land development and the construction of the Sultan Mahmud Bridge completed in 1990, they were merged into one large island with Pulau Kambing towards the east. Furthermore, the terrain structure of Kampung Pulau Duyong as a whole is a flat surface. The locals maintain the Malay culture and way of life, with over $40 \%$ of the population working as fishermen.

Kampung Losong is located near the Kuala Terengganu river with 11 sub-villages opposite Pulau Wan Man. Historically, the villagers of Kampung Losong are well-known for their expertise in marine sciences passed down by the Bugis community. At the same time, the local people of Kuala Terengganu are also skilled in carpentry. As a result, these skills were cleverly combined to produce high-quality boats. Significant roles played by boat-making activities in the early 18th and late 19th centuries have transformed Kuala Terengganu into an international trading port. The socio-economic activities of the Kampung Losong villagers are songket textile businesses, smallscale trading, and fishing. Nowadays, the village is growing exponentially, with more people working in the city and managing small businesses.

The main reason why Kampung Losong and Pulau Duyong Village was selected for this study as both villages have similarities in terms of traditional Malay cultural characteristics and values. In general, the presence of traditional villages around the city of Kuala Terengganu conveys the socio-cultural identities of genuine Malay communities through the relationship between the choice of location of settlements, architectural design, the layout setting, climate and it is surrounding.

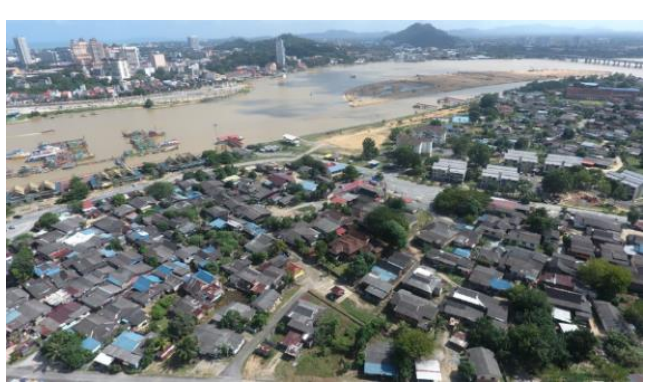

(a)

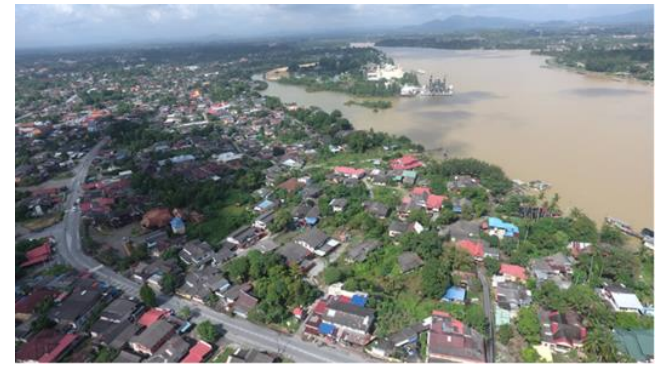

(b)

Fig. 1. Settlement layout of Kampung Pulau Duyong (a) and Kampung Losong (b) (Source: Author, 2019)

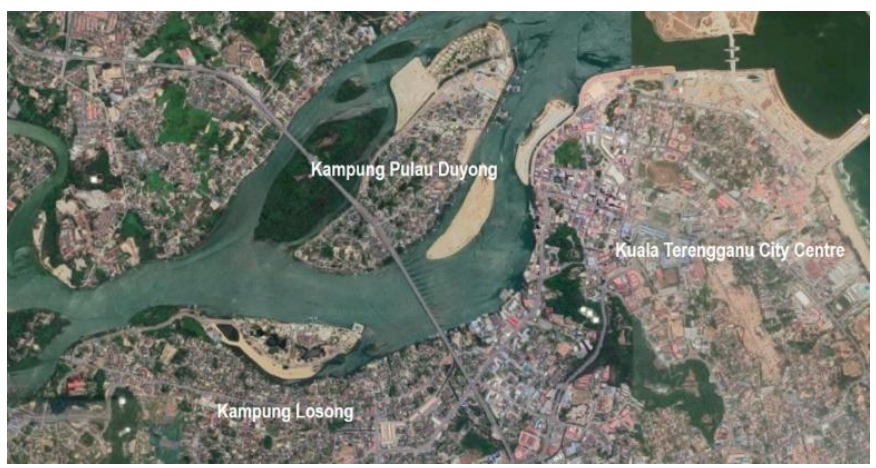

Fig. 2. Map of the study area

(Source: Google Maps, 2020) 


\subsection{Data collection and data analysis}

The quantitative approach involved a series of survey forms distributed to over 400 respondents comprising local residents. Respondents were asked to evaluate the physical attributes criteria affecting social sustainability on a 5-point Likert scale ("1" = strongly disagree and "5" = strongly agree). Cluster sampling was applied to complete this study. Cluster sampling is a method for data collection for a sampling method where the participants of the population are selected at random. All the respondents were chosen from randomly selected clusters. For this study, the sample used was local residents living in Kampung Pulau Duyong and Kampung Losong consisting of more than 800 local residents' houses in total, where the majority are Malays. The data gained from the questionnaire survey were analyzed using descriptive analysis used in the Social Science Statistics Package (SPSS) version 25. To summarize, descriptive statistics and inferential analysis are used to describe data in the form of numerical calculations, charts, and tables. Factor analysis and reliability analysis were adopted in this study to analyze the data. Factor analysis was used to identify the underlying values of public spaces in accomodating social sustainability.

\subsection{Reliability}

Reliability analysis was also used to study the factors in this study. It is concerned with determining the validity of construction. Reliability analysis is invaluable in measuring the level of scepticism or consistency of an estimated scale called Cronbach's alpha (a). Through internal reliability consistency assessment, Cronbach's alpha values for infrastructure facilities 0.55 . These values exceed 0.5 which is said to have a satisfactory level of consistency.

\subsection{Findings}

\subsection{Residents profile}

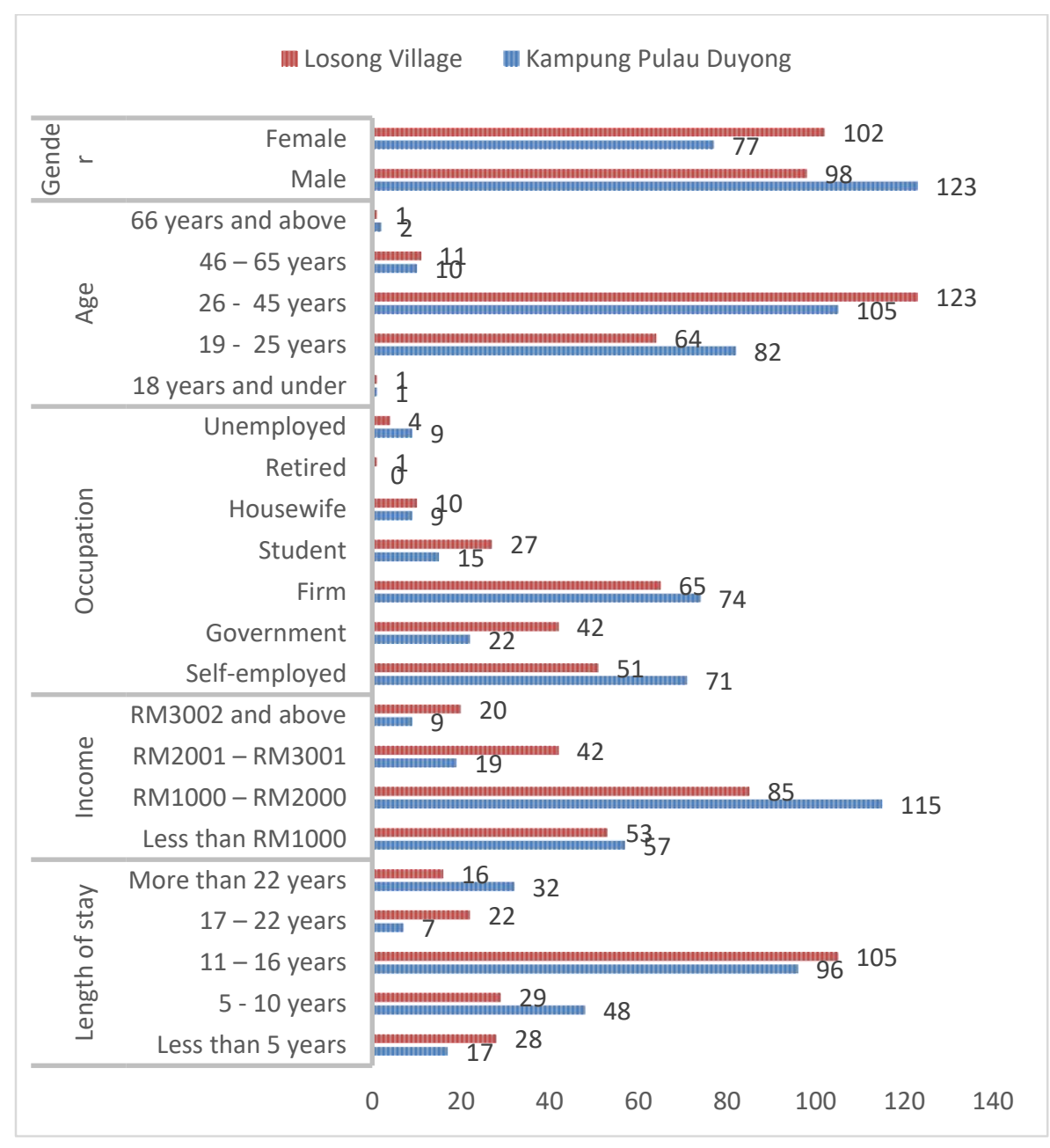

Fig. 2: Respondent's profile (Source: Authors, 2020) 
The figures below report the results from the questionnaire survey conducted in Kampung Pulau Duyong and Kampung Losong. A total of 800 respondents participated in the survey. Most of Kampung Pulau Duyong respondents were male (61.5\%), while in Kampung Losong, most residents were female (51\%). A majority of the respondents were between 17 - 70 years old with almost fair distribution among gender. The results indicated that both settlements had a greater number of adult-youth respondents between $26-45$ years old. A large percentage of respondents work in the private sector (KPD, 37\% and $\mathrm{KL}, 32.5 \%$ ) and self-employed (KPD, $35.5 \%$ and $\mathrm{KL}$, $25.5 \%$ ), as seen from both respondents in the survey groups. Less than $20 \%$ were students, housewives, retirees, and unemployed. The majority of respondents are from the middle-income group, earning RM1000-RM2000 a month. However, there is a significant difference whereby the Kampung Losong population has more income percentage of RM2001-3001 compared to the Kampung Pulau Duyong population. There were more than $65 \%$ of respondents that have been residing in both villages for 11 years and above.

\subsection{Typologies of public infrastructure}

Based on the analysis of the questionnaire and the results of the survey, the study found that social interaction at public infrastructures seemed to be influenced by the respondent's background including gender and employment status. Respondents from different groups use public infrastructure for different reasons. Adults and the elderly prefer passive activities such as sitting, reading, eating, and sightseeing. They mostly talk to their friends, share experiences with their peers, and observe people's behaviour. This group feels more comfortable in their group without the presence of outsiders. While youths and children are more inclined to explore open space due to their curiosity and enthusiasm in exploring the environment to strengthen their social support, whereas parents use this space to improve their quality of life and life expectancy.

Among the public infrastructure mostly used by the population consists of fields, children's playgrounds, and historic sites. The strategic field area near the jetty is also known as a tourist attraction. The field covers an area of 0.2 hectares with a capacity of 300 to 1000 people. There is also a playground for children under 12 years old. The inclusion of passive activities combined with active activities has contributed to the success of public infrastructure in Kampung Pulau Duyong. Among the passive activities identified through observation are observing, sightseeing, basking in nature, walking, running, kite flying, fishing, and exploring the historic site of Kota Lama Duyong located nearby the field area. On the other hand, active activities consist of playing football and futsal. Apart from this, various events such as festivals, poem recitals, forums, and cultural shows are held using the available field area. The location of public infrastructure by the riverfront has made Kampung Pulau Duyong a settlement with a comfortable public space in line with the findings of Abdul Rahman, Shamsuddin, and Ghani (2015). Their study found that public infrastructure should serve as a ceremonial space, node, and landmark.

While in Kampung Losong, its public infrastructure consists of concrete grounds and fields by the roadside at the end of the settlement. The Civic Hall and Community Hall facilities located in one place were also selected as infrastructure that accommodates large-scale activities. The public infrastructure is dominated by youths and children with active activities in the evening. While public spaces such as platforms or 'pangkin' are dominated by adults and the elderly with a variety of passive activities. With this result, the study found that both settlements have a similar pattern of activities and groups regarding the use of public infrastructure.

\begin{tabular}{|c|c|c|c|}
\hline Social sustainability indicator & Factor loading & $\begin{array}{l}\% \text { of variance } \\
\text { explained }\end{array}$ & $\begin{array}{l}\text { Cumulative } \% \text { of the } \\
\text { variance }\end{array}$ \\
\hline Recreation space & & 2.579 & 63.901 \\
\hline $\begin{array}{l}\text { Provide sufficient facilities and space to accommodate } \\
\text { sports and recreational activities }\end{array}$ & 0.806 & & \\
\hline Communal space & & 2.910 & 61.322 \\
\hline Accommodates different activities at different times & 0.747 & & \\
\hline $\begin{array}{l}\text { Provides facilities to the public to enjoy comfort and } \\
\text { tranquillity }\end{array}$ & 0.614 & & \\
\hline
\end{tabular}

(Source: Authors, 2020)

\subsection{Discussion}

\subsection{Availability of facilities and space to accommodate sports and recreational activities}

The open space available at Kampung Pulau Duyong is a field located strategically near the jetty known as a tourist attraction. The field has an area of 0.2 hectares with a capacity of 300 to 1000 people. There is also a playground for children under 12 years old. The inclusion of passive activities combined with active activities has contributed to the success of the open space in Kampung Pulau Duyong. Among the passive activities identified through observation are observing, sightseeing, basking in nature, walking, running, kite flying, fishing, and exploring the historic site of Kota Lama Duyong located nearby the field area. Active activities consist of playing football and futsal. Apart from this, various events such as festivals, poetry recitals, forums, and cultural shows are held using the available field area. Furthermore, the recreational facilities offered in the field and other support facilities such as ample seating and shade in the surrounding area often meet the needs of every resident. The location of open space in front of the river has made Kampung Pulau Duyong unmatched by other recreational areas that usually have an uninteresting view. This study found that open space should serve as a ceremonial space, nodes, and landmarks.

While in Kampung Losong, open spaces are grounds and fields located next to the road at the end of the settlement. The Civic Hall and Community Hall facilities located in one place make it easy to accommodate large-scale activities. The open space is dominated by 
youths and children with active activities in the evening. With this result, the study found that both settlements have a similar pattern of activities and groups utilizing the open space. With adequate facilities, more activities can take place and more people have the opportunity to participate. According to the observation data, Kampung Losong was a bit lack of green open spaces near the settlement area. As open spaces have an important in neighbourhood life in fostering social interactions that are elemental for social cohesion and encourage a sense of community. Without open green spaces, the temperature increases and impact on environmental loss. The reclamation land along the river of Kampung Losong give effects which increase the noise pollution through the existence of the main road due to closer to the Kuala Terengganu Town, as well as lead to the deterioration of the cultural heritage value. Even though, the new development along the river allows social welfare to enhanced through providing the facilities and infrastructure and have the potential to be a public recreation space and mixed development, nevertheless, the transformation of the heritage environment through redevelopment is thought to have caused in the deterioration of the image quality, biodiversity and environmental stability.

Overall, the facilities and area of the public space in Kampung Pulau Duyong and Kampung Losong are sufficient with a good balance to accommodate the capacity of the community among the two genders and can be used by all groups of people including the elderly, adults and children. The public space in Kampung Pulau Duyong and Kampung Losong can be used by individuals and groups that improve the quality of socializing and is more enjoyable. This coincides with the statement of Sakip, Akhir, and Omar (2015) whereby public space should meet the needs of all its users.

\subsection{Accommodating different activities at different times}

Studies show that successful public infrastructure is influenced by physical, activity, design, history, and culture that is still practised. The most vital factor is that public space can accommodate different activities at different times, is to enjoy tranquillity comfortably, and have adequate facilities. These factors can create daily interactions, encompass all groups of people, and maintain privacy among different groups. This study discovers a social perspective on public infrastructure, as stated by Karimnia \& Haas (2020) whereby the way people use the various spaces is important based on different cultures, genders, interests that shape social interactions and societal relationships. The results of the study are also in line with Gehl's (2002) statement wherein facilities and equipment are significant factors that play a role in providing satisfaction to users of public infrastructure. This study emphasizes that the interior space and public infrastructure environment in traditional settlements should have formal or informal seating amenities to create opportunities for social interaction. As highlighted by Barrera et al. (2016), responsive public infrastructure is a flexible space for various events and as a space that provides a wide selection of activities.

Table. 2. Typologies of activities

\begin{tabular}{ll}
\hline Activities & Example \\
\hline Recreation & Walking, exercising, relaxing, observing, playing \\
In Groups & Gathering with family and friends, children playing together, hawker groups \\
Seasonal Programs & Merdeka celebration, Maulidur Rasul celebration, competitions, Cultural Day festival \\
Daily Activity & Tourists, hawkers, children playing, relaxing, resting \\
Entertainment & Playing musical instruments, poetry, concerts \\
Economy & Selling daily or during seasonal events
\end{tabular}

(Source: Authors, 2020)

\subsection{Provides facilities to the public to enjoy comfort and tranquillity}

Based on the observations, the study shows that physical, activity, social, and design factors influence the social interaction of public infrastructure in both settlements. Factors that are seen as fundamental that create comfort and tranquillity are physical, visual appeal, location, security, and accessibility influence social interaction at public infrastructure. The results of this study are in line with the opinion of Barrera et al. (2016) wherein the accessibility of public infrastructure is an influential factor in improving the quality of social interaction. The strategic location of public infrastructure chosen by the residents is near the main road and the settlement area. The results of this study also conform with the statements of Pasaogullari and Doratli (2004), and Sugiyama and Thompson (2007) stating that good public infrastructure is located in neighbourhoods and workplaces, easily accessible, and can be monitored from the road.

\subsection{Limitation of the study}

The following are the limitations related to the study. The discussion is mainly in the context of the physical characteristic of public infrastructures, another indicator of social sustainability is not studied. Furthermore, the study location only focuses on the traditional Malay settlement, thereby other ethnic settlements were not studied.

\subsection{Conclusion and Recommendations}

In conclusion, a successful public infrastructure is also a space that is easily accessible, establishes social connections, provides a variety of events and activities, with an attractive design, and creates a sense of belonging. Lastly, social relationships are crucial for communities in a settlement because strong community relationships will encourage individuals to cooperate in achieving prosperity.

This study proves that conservation efforts focused on the physical landscape is intended to give an idea and efforts regarding the importance of preserving social sustainability in a traditional Malay settlement population. Preservation and conservation efforts of the 
physical landscape are important because it reflects the community's sustainability of a society with an identity. This can be achieved by distinguishing the community activities that are still practised in traditional settlements

It is suggested that further research be carried out within the field of social sustainability, Malay cultural landscape, and its related areas. Several research topics that can be investigated related to the study are as follows: (i) the study on the determinant factors to enhance safety, quality of surrounding, accessibility and identity (ii) study on other countries which have a different life of style and cultural activities.

\section{Acknowledgements}

I would like to dedicate this paper to the dwellers of Kampung Pulau Duyong and Kampung Losong. Thanks to all the respondents for accessing me to observe their houses and their time for interviews. Finally, thanks to the Institute of the Malay World and Civilization, The National University of Malaysia. This work was accomplished in part with funding from Grant DCP-2017-008/3.

\section{Paper Contribution to Related Field of Study}

This paper also contributes to other related main fields of studies such as Urban Design, Landscape Design, Conservation of historical sites and Social Psychology.

\section{References}

Ariffin, N. F. M. (2007). Role of the cultural landscape in improving the identity of the Kuala Terengganu Town centre as a Malay historic town (Doctoral dissertation, Universiti Teknologi Malaysia).

Authority, L. G. (2011). Pelan Induk Kampung Tradisional dan Petempatan Tersusun di Dalam Kawasan Pihak Berkuasa Tempatan Semenanjung Malaysia.

Bardis, P. D. (1979). Social interaction and social processes. Social Science, 54(3), 147-167.

Barrera, F., Reyes-Paecke, S., Harris, J., Bascuñán, D., \& Farías, J. M. (2016). People's perception influences on the use of green spaces in socio-economically differentiated neighborhoods. Urban Forestry \& Urban Greening, 20, 254-264.

Berglee, R. (2012). World regional geography: People, places and globalization.

Bobek, H., \& Schmithüsen, J. (1998). A paisagem e o sistema lógico da geografia. CORREAA, RL.

de Sousa Silva, C., Viegas, I., Panagopoulos, T., \& Bell, S. (2018). Environmental justice in accessibility to green infrastructure in two European cities. Land, 7(4), 134.

Davidson, M. (2009). Social sustainability: a potential for politics?. Local Environment, 14(7), 607-619.

Festinger, L. (1950). others, Theory and Experiment in Social Communication. Ann Arbor.

Gehl, J. (2002). Public spaces and public life: City of Adelaide, 2002. City of Adelaide, Adelaide.

Ghoomi, H. A., Yazdanfar, S. A., Hosseini, S. B., \& Maleki, S. N. (2015). Comparing the components of sense of place in the traditional and modern residential neighborhoods. Procedia-Social and Behavioral Sciences, 201, 275-285.

González, D., Henriquez, B., \& Sierra, L. (2020). Evaluation of the Social Sustainability of Infrastructure Projects: A Case Study of Urban Road Improvement in Southern Chile. In IOP Conference Series: Earth and Environmental Science (Vol. 503, No. 1, p. 012002). IOP Publishing.

Kader, A., \& Mahmoud, R. A. (2019). Strategies for Urban Residual Areas as a Planning Tool: Towards Achieving Sustainable Built Environment by Connecting Neighbourhoods. In IOP Conference Series: Earth and Environmental Science (Vol. 329, No. 1, p. 012018). IOP Publishing.

Karimnia, E., \& Haas, T. (2020). APPROPRIATION OF PUBLIC SPACE. Companion to Public Space.

Leibenath M, Gailing L (2012) Semantische Anna herung an dieWorte „Landschaft“und „Kulturlandschaft“. In: SchenkW, Ku'hn M, Leibenath M, Tzschaschel S (eds) SuburbaneRaüume als Kulturlandschaften. Verlag der ARL, Han-nover, pp 58-79

Lotfata, A., \& Ataöv, A. (2020). Urban streets and urban social sustainability: a case study on Bagdat street in Kadikoy, Istanbul. European Planning Studies, 28(9), 17351755.

McKenzie, S. (2004). Social sustainability: towards some definitions.

Michael, Y. M. A. K., \& PEACOCK, C. J. (2011). Social Sustainability: A Comparison of Case Studies in UK, USA and Australia.

Moulay, A., Ujang, N., \& Said, I. (2017). Legibility of neighborhood parks as a predicator for enhanced social interaction towards social sustainability. Cities, 61, 58-64.

Parker, J., \& Simpson, G. D. (2018). Public green infrastructure contributes to city livability: A systematic quantitative review. Land, 7(4), 161.

Pasaogullari, N., \& Doratli, N. (2004). Measuring accessibility and utilization of public spaces in Famagusta. Cities, 21(3), 225-232. 
Pickering, M. (1994). The physical landscape as a social landscape: a Garawa example. Archaeology in Oceania, 29(3), $149-161$.

Rahman, N. A., Shamsuddin, S., \& Ghani, I. (2015). What makes people use the street?: Towards a liveable urban environment in Kuala Lumpur City Centre. ProcediaSocial and Behavioral Sciences, 170, 624-632.

Rapoport, A. (1976). Sociocultural aspects of man-environment studies. The Mutual Interaction of People and Their Environment, 7-35.

Rasdi, M. T. H. M. (2011). Krisis pemikiran seni bina Malaysia. Penerbit UTM Press.

Sakip, S. R. M., Akhir, N. M., \& Omar, S. S. (2015). Determinant factors of successful public parks in Malaysia. Procedia-Social and Behavioral Sciences, $170,422-432$. Sauer, C. (1963). 0.(1925). The morphology of landscape. University of California publications in geography, 2(2), $19-54$.

Sugiyama, T., \& Thompson, C. W. (2007). Older people's health, outdoor activity and supportiveness of neighbourhood environments. Landscape and Urban Planning, $83(2-3), 168-175$

Shamsuddin, S., Sulaiman, A. B., \& Amat, R. C. (2012). Urban landscape factors that influenced the character of George Town, Penang UNESCO World Heritage Site. Procedia-Social and Behavioral Sciences, 50, 238-253.

Wei, L. (2015). Research on the localization method of protecting traditional village landscape: a case study on tangyin. International Archives of the Photogrammetry, Remote Sensing \& Spatial Information Sciences, 40.

Woodcraft, S., Hackett, T., \& Caistor-Arendar, L. (2011). Design for social sustainability: A framework for creating thriving new communities. Future Communities. 